\title{
Modeling the Ionosphere during Quiet Time Variation at Ouagadougou in West Africa
}

\author{
Emmanuel Nanema ${ }^{1,2}$, Doua Allain Gnabahou ${ }^{2}$, Christian Zoundi², Frédéric Ouattara ${ }^{2}$ \\ ${ }^{1}$ Centre National de la Recherche Scientifique et Technologique (CNRST), Institut de Recherche en Sciences Appliquées et \\ Technologies (IRSAT), Ouagadougou, Burkina Faso \\ ${ }^{2}$ Laboratoire de Recherche en Météorologie de l'Espace (LAREME), Université Norbert ZONGO, Koudougou, Burkina Faso \\ Email: nanema_emmanuel@yahoo.fr
}

How to cite this paper: Nanema, E., Gnabahou, D.A., Zoundi, C. and Ouattara, F. (2018) Modeling the Ionosphere during Quiet Time Variation at Ouagadougou in West Africa. International Journal of Astronomy and Astrophysics, 8, 163-170. https://doi.org/10.4236/ijaa.2018.82011

Received: March 2, 2018

Accepted: June 4, 2018

Published: June 7, 2018

Copyright (c) 2018 by authors and Scientific Research Publishing Inc. This work is licensed under the Creative Commons Attribution International License (CC BY 4.0).

http://creativecommons.org/licenses/by/4.0/

\section{(c) (i) Open Access}

\begin{abstract}
Ionosphere parameters determination is used to characterize its composition in particles. These results have been compared to data curried from Ouagadougou station. The present study deals with Total Electron Contents (TEC) results determined by Thermosphere-Ionosphere-Electrodynamics General Circulation Model (TIEGCM) version 1.94 and International Reference Ionosphere (IRI) version 2012 during solar cycle 22. The minimum and maximum phases of solar cycle 22 are considered in this study for TEC determination. The station is located at Ouagadougou, in western Africa, characterized by its latitude $\left(12.4^{\circ} \mathrm{N}\right)$ and longitude $\left(358.5^{\circ} \mathrm{E}\right)$. The present study completes the two previous articles on hmF2 and foF2 parameters determination on the same station by comparison between TEC results carried out from TIEGCM and IRI models. So that, quiet time condition is determined by $\mathrm{Aa}(\leq 20 \mathrm{nT})$ for the five quietest days in each characteristic month of seasons. $\mathrm{Rz}$ values characterize minimum and maximum solar cycle phases.
\end{abstract}

\section{Keywords}

Ionosphere, TEC, Solar Cycle Phases, TIEGCM, IRI

\section{Introduction}

During the recent two decades several works deal with the modeling of the ionosphere parameters [1]-[12]. For the modeling, many authors used several models [13]-[26].

TIEGCM is a model developed at the National Center for Atmospheric Research (NCAR, Boulder, Colorado State, USA). Running this model can help to 
determine different parameters of the ionosphere (considered as the plasma) such as the TEC. Ionization phenomena in the ionosphere determine the TEC.

IRI model can be easily run in the internet.

The interest of this work is that it is the first time an Africa Equatorial Ionization Anomaly (EIA) station is investigated by TIEGCM model with TEC parameter. The knowledge of ionosphere parameters can help to the best understanding of climate change because of ionization effects. Ionosphere behaviors like a plasma.

In this paper, quiet time conditions are considered. Solar cycle phase impact is analyzed by taking into account the minimum (1985) and maximum (1990) of solar cycle 22. The other solar cycle phases are not used here like during Ouattara (2013) study because generally TIEGCM is running under solar minimum and maximum conditions. Seasonal effect is also investigated by analyzing equinoctial (March and September) and solstice (June and December) months predicted and TEC results variability.

\section{Materials and Methods}

TEC results are analyzed under quiet time conditions determined by using geomagnetic aa index values. In previous studies, we determined hmF2 [27] and foF2 [28] by use of TIEGCM (Thermosphere Ionosphere Electrodynamics General Circulation Model) and IRI (International Reference Ionosphere) models. The quiet time periods are determined by considering Aa $\leq 20 \mathrm{nT}$. We consider in the present paper the five quietest days results per chosen month. The present study also considers seasons and solar cycle phases. Equinox months are March and September and solstice months are June and December. Solar phases are obtained by applying the following criteria [29] [30] [31]: 1) minimum phase: $\mathrm{Rz}$ $<20$, where $\mathrm{Rz}$ is the yearly average Zürich Sunspot number; 2) ascending phase : $20 \leq \mathrm{Rz} \leq 100$ and $\mathrm{Rz}$ greater than the previous year value; 3) maximum phase : $\mathrm{Rz}>100$ [for small solar cycles (solar cycles with sunspot number maximum ( $\mathrm{Rz}$ max) less than 100) the maximum phase is obtained by considering $\mathrm{Rz}>0.8 \mathrm{Rz} \max$ ]; and 4) descending phase: $100 \geq \mathrm{Rz} \geq 20$ and $\mathrm{Rz}$ less than the previous year's value. The maximum year is 1990 and the minimum year 1985 .

For the comparison between TEC values, we used, for a given month, the arithmetic mean values for the five quietest days. Table 1 gives the retained days.

Predicted values are obtained by running TIEGCM for the selected days under solar maximum condition given by F10.17 $=200$ and solar minimum condition expresses by F10.7 = 70 for local point determining by its geographic longitude, latitude and local time. We do not consider all solar cycle phase as the model generally is running for both solar maximum and minimum conditions.

TIEGCM integrates 174 values for longitude and 72 values for latitude. The position of Ouagadougou station is not exactly held by the model. Yet, closest values to Ouagadougou station parameters are used after interpolation. It is important to precise that this method does not introduce significant error in the 
Table 1. Retain days for the study.

\begin{tabular}{ccccccc}
\hline \multicolumn{1}{c}{ Months } \\
\hline $\begin{array}{l}\text { Solar } \\
\text { cycle }\end{array}$ & Phase & Year & $\begin{array}{c}\text { March } \\
\text { (Equinox) }\end{array}$ & $\begin{array}{c}\text { June } \\
\text { (Solstice) }\end{array}$ & $\begin{array}{c}\text { September } \\
\text { (Equinox) }\end{array}$ & $\begin{array}{c}\text { December } \\
\text { (Solstice) }\end{array}$ \\
& Min & 1985 & $9,13,21,22,25$ & $3,14,16,18,19$ & $2,3,4,5,29$ & $8,9,21,23,29$ \\
C22 & Max & 1990 & $4,10,16,17,31$ & $16,17,20,21,30$ & $2,3,27,29,30$ & $10,11,19,21,29$ \\
\hline
\end{tabular}

model result of TEC because there is small difference between magnetic and geographic longitude at low latitudes.

TEC prediction accuracy is appreciated by analysis hourly plots variability. For plots variability analysis error bars will help us. Error bars are obtained by applying $\sigma=\sqrt{\Delta}$ where $\Delta$ is the variance defined by $\frac{1}{N} \sum_{i=1}^{N}\left(x_{i}-\bar{x}\right)^{2}$ with $\bar{x}$ mean value and $\mathrm{N}$ the total number of observations for a particular dataset.

\section{Results and Discussion}

Figure 1 (Panels (a), (b), (c), (d)) gives the time variation of TEC for solar minimum (year 1985) and Figure 2 (panels (a'), (b'), (c'), (d')) presents the time variation of TEC for solar maximum (year 1990) of C22. Blue curve concerns TEC results after running TIEGCM model and red curve is for TEC results given by IRI model.

On solar minimum, TEC profiles show Reversed profiles for TIEGCM TEC values for both equinox and solstice seasons while noon bite out profiles appear on December, June and March for TEC values under IRI running condition. Reversed profile is observed for this model on September.

During solar maximum phase, Morning Peak, Reversed and Dome profiles are observed respectively on December, Reversed for both June and September and Dome on March for Tec values given by TIEGCM running. IRI model focuses two profiles which are Plateau on December and March and Dome on June and September.

These profiles express the signature of electric current. In fact, Reversed profile is due to the presence of the intense counter electrojet while Dome and Plateau profiles highlight the absence of the electrojet [32] [33]. This shows that only daytime effects cannot explain Reversed profile.

These profiles show suitable results with those found by use of TIEGCM and IRI for determination of NmF2 and foF2 profiles in the same conditions on maximum and minimum phases of solar cycle 22.

This study also shows at least that TEC parameters in the ionosphere are not only due to the daytime effects. This is previously highlighted in the study of NmF2 and foF2.

In Figure 3 (panel (a"), TEC mean values given by TIEGCM model is compared to those given by IRI model for minimum solar cycle phase of C22. Panel 


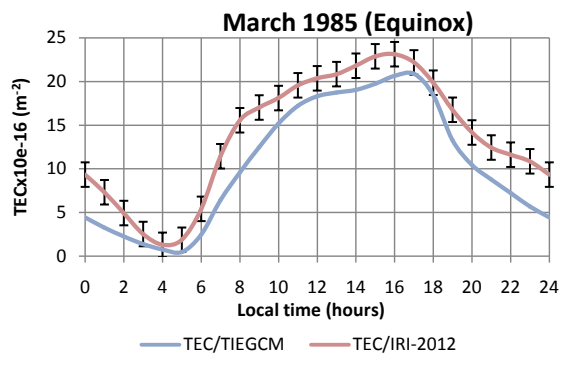

(a)

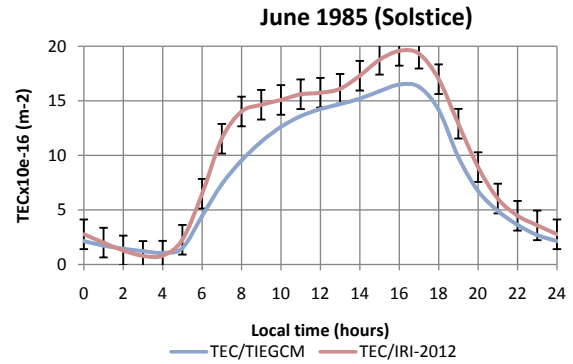

(c)

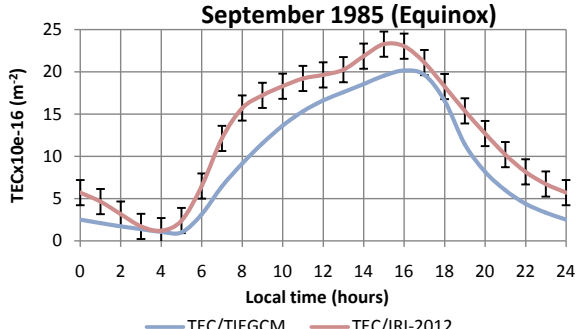

(b)

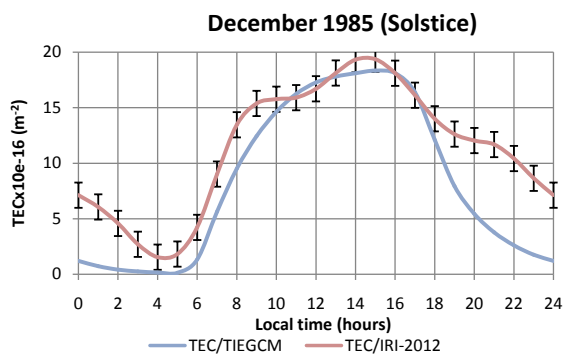

(d)

Figure 1. Time variation of TEC on minimum solar cycle phase of C22. (a) TEC profiles given by TIEGCM and IRI on March 1985; (b) TEC profiles given by TIEGCM and IRI on September 1985; (c) TEC profiles given by TIEGCM and IRI on June 1985; (d) TEC profiles given by TIEGCM and IRI on December 1985.

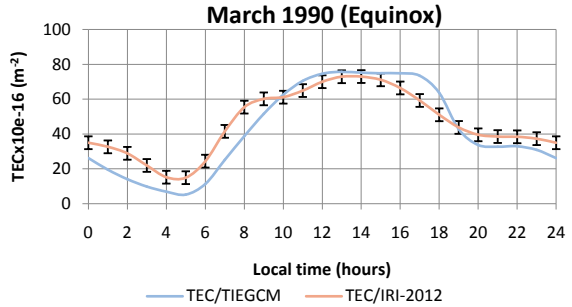

(a)

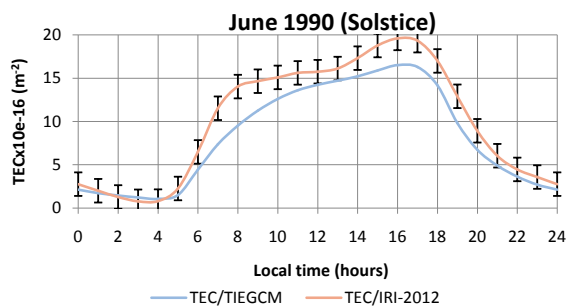

(c)

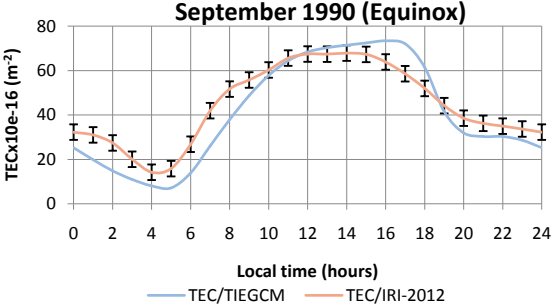

(b)

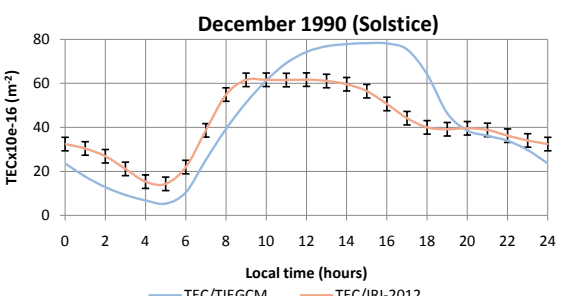

(d)

Figure 2. Time variation of TEC on maximum solar cycle phase of C22. TEC profiles given by TIEGCM and IRI on March 1990; TEC profiles given by TIEGCM and IRI on September 1990; TEC profiles given by TIEGCM and IRI on June 1990; TEC profiles given by TIEGCM and IRI on December 1990.

(b") shows the comparison during solar maximum phase at the same cycle.

Figure 3 shows that between TIEGCM and IRI models, TEC values are given with mean relative error variation in the range of [18]-[28] on minimum solar cycle phase. This range is [3]-[8] on maximum solar cycle phase. 


\section{TEC MEAN VALUES PER MONTH \\ DURING MINIMUM SOLAR CYCLE \\ PHASE (1985)}

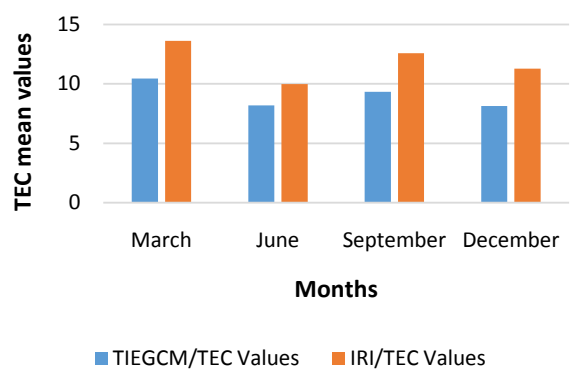

(a)

\section{TEC MEAN VALUES PER MONTH \\ DURING MAXIMUM SOLAR CYCLE \\ PHASE (1990)}

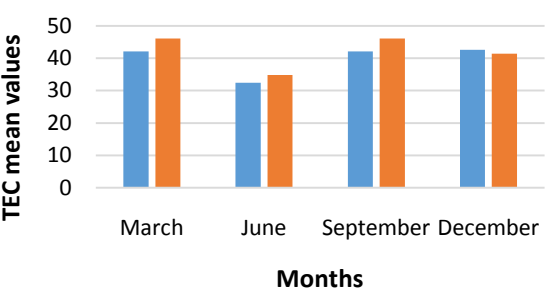

-TIEGCM/TEC Values IRI/TEC Values

(b)

Figure 3. Comparison of TEC mean values given by TIEGCM and IRI models; (a) Comparison of TEC mean values given by TIEGCM and IRI models on minimum solar cycle phase (1985); (b) Comparison of TEC mean values given by TIEGCM and IRI models on maximum solar cycle phase (1990).

These ranges of mean relative error of TEC variation per month show that TIEGCM and IRI models give approximate values on maximum solar cycle phase. On minimum solar cycle phase, TEC values present great differences.

The conclusion we can find out from these comparisons is that TIEGCM and IRI models are almost suitable on maximum solar cycle phase for TEC determination.

\section{Conclusion}

TEC results given by TIEGCM and IRI models at Ouagadougou station on minimum and maximum solar cycle phases present different profiles previously found by other authors. The two models are suitable for TEC determination at maximum solar cycle phase but have bad correlation on minimum solar cycle phase. We have found the same result for foF2 study in comparison between data, TIEGCM and IRI.

\section{Aknowledgements}

Authors thank Pr. Arthur D. Richmond and Dr. Astrid Maute for their help during the stay at High Altitude Observatory (Denver, Colorado, 2013). They also thank Dr. Rolland Fleury for his assistance at Télécom Bretagne during the study tour on 2017.

\section{References}

[1] Bittencourt, J.A. and Chryssafidis, M. (1994) On the IRI Model Predictions for the Low-Latitude Ionosphere. Journal of Atmospheric and Solar-Terrestrial Physics, 56, 995-1009. https://doi.org/10.1016/0021-9169(94)90159-7

[2] Abdu, M.A., Batista, I.S, and de Souza, J.R. (1996) An Overview of IRI-Observational Data Comparison in American (Brazilian) Sector Low Latitude Ionosphere. Advances in Space Research, 18, 13-22.

https://doi.org/10.1016/0273-1177(95)00893-4 
[3] Batista, I.S., Abdu, M.A., de Medeiros, R.T., and de Paula, E.R. (1996) Comparison between IRI Predictions and Digisonde Measurements at Low Latitude Station. Advances in Space Research, 18, 49-52. https://doi.org/10.1016/0273-1177(95)00899-3

[4] Pandey, V.K. and Sethi, N.K. (1996) Comparison ofhmF2 and Midday Bottom Side Electron Density Profile Obtained from IRI and Incoherent Scatter Measurements. Advances in Space Research, 18, 33-37. https://doi.org/10.1016/0273-1177(95)00895-0

[5] Shastri, S., Aggarwal, S. and Sethi, N.K. (1996) Performance of IRI Model Predictions of F-Region for Indian latitudes. Advances in Space Research, 18, 41-44. https://doi.org/10.1016/0273-1177(95)00897-7

[6] Souza, J.R., de Bailey, G.J., Abdu, M.A. and Batista, I.S. (2003) Comparison of Low Latitude F Region Peak Densities, Heights and Equatorial ExB Drift from IRI with Observational Data and the Sheffield University Plasmasphere Ionosphere Model. Advances in Space Research, 31, 501-505. https://doi.org/10.1016/S0273-1177(03)00050-4

[7] Jin, S. and Park, J.U. (2007) Ionospheric Tomography: A Comparison with the IRI-2001 Model over South Korea. Earth Planet Space, 59, 287-292. https://doi.org/10.1186/BF03353106

[8] Bhuyan, P.K. and Borah, R.R. (2007) TEC Derived from GPS Network in India and Comparison with the IRI. Advances in Space Research, 39, 830-840. https://doi.org/10.1016/j.asr.2006.12.042

[9] Sethi, N.K., Dabas, R.S. and Das, R.M. (2007) Diurnal and Seasonal Variations of B0, B1 Parameters during High Solar Activity Period at Low Mid-Latitude and Their Comparison with IRI-2001 Model. Journal of Atmospheric and Solar-Terrestrial Physics, 69, 767-774. https://doi.org/10.1016/j.jastp.2007.01.008

[10] Adewale, A.O., Oyeyemi, E.O. and Akala, A.O. (2010a) Comparison of Neutral Network Technique with IRI-2001 Model Ionospheric Predictions during Great Geomagnetic Storms for Middle Latitude Station. Journal of Scientific Research and Development, 12, 75-92.

[11] Adewale, A.O., Oyeyemi, E.O. and Ofuase, U.D. (2010b) Comparison between Observed foF2 and IRI-2001 Predictions over Periods of Sever Geomagnetic Activities at Grahamstown South Africa. Advances in Space Research, 45, 368-373.

[12] Ouattara, F. and Rolland, F. (2011) Variability of CODG TEC and IRI 2001 Total Electron Content (TEC) during IHY Campaign Period (21 March to 16 April 2008) at Niamey under Different Geomagnetic Activity Conditions. Scientific Research and Essays, 6, 3609-3622. https://doi.org/10.5897/SRE10.1050

[13] Sethi, N.K., Pandey, V.K. and Mahajan, K.K. (2001) Comparative Study of TEC with IRI Model for Solar Minimum at Low Latitude. Advances in Space Research, 27, 45-48. https://doi.org/10.1016/S0273-1177(00)00139-3

[14] Sethi, N.K., Dabas, R.S., and Vohra, V.K. (2004) Diurnal and Seasonal Variations of HmF2 Deduced from Digital Ionosonde over New Delhi and Its Comparison with IRI 2001. Annals of Geophysics, 22, 453-458. https://doi.org/10.5194/angeo-22-453-2004

[15] Bhuyan, P.K., Chamua, M., Bhuyan, K., Subrahmanyam, P. and Garg, S.C. (2003) Diurnal, Seasonal and Latitudinal Variation of Electron Density in the Topside F-Region of the Indian Zone Ionosphere at Solar Minimum and Comparison with the IRI. Journal of Atmospheric and Solar-Terrestrial Physics, 65, 359-368. https://doi.org/10.1016/S1364-6826(02)00294-8 
[16] Batista, I.S. and Abdu, M.A. (2004) Ionospheric Variability at Brazilian Low and Equatorial Latitudes: Comparison between Observations and IRI Model. Advances in Space Research, 34, 1894-1900. https://doi.org/10.1016/j.asr.2004.04.012

[17] Bertoni, F., Sahai, Y., Lima, W.L.C, Fagundes, P.R., Pillat, V.G., Becker-Guedes, F. and Abalde, J.R. (2006) IRI-2001 Model Predictions Compared with Ionospheric Data Observed at Brazilian Low Latitude Stations. Annals of Geophysics, 24, 2191-2200.

[18] MiroAmarante, G., CXuetoSantamaria, M., Alazo, K. and Radicella, S.M. (2007) Validation of the Storm Model Used in IRI with Ionosonde Data. Advances in Space Research, 39, 681-686. https://doi.org/10.1016/j.asr.2007.01.072

[19] Rios, V.H., Medina, C.F. and Alvarez, P. (2007) Comparison between IRI Predictions and Digisonde Measurements at Tucuman. Journal of Atmospheric and Solar-Terrestrial Physics, 69, 569-577.

[20] Ouattara, F. (2013) IRI-2007 foF2 Predictions at Ouagadougou Station during Quiet Time Periods from 1985 to 1995. Archives of Physics Research, 4, 12-18.

[21] Ouattara, F. and Nanéma, E. (2013) hmF2 Quiet Time Variations at Ouagadougou and Comparison with IRI-2012 and TIEGCM Predictions during Solar Minimum and Maximum. Archives of Applied Science Research, 5, 55-61.

http://www.scholarsresearchlibrary.com

[22] Ouattara, F., Gnabahou, A. and Amory Mazaudier, C. (2012) Seasonal, Diurnal and Solar-Cycle Variations of Electron Density at Two West Africa Equatorial Ionization Anomaly Stations. International Journal of Geophysics, 2012, Article ID: 640463.

[23] Pedatella, N.M., Forbes, J.M., Maute, A., Richmond, A.D., Fang, T.-W., Larson, K.M. and Millward, G. (2011) Longitudinal Variations in the F Region Ionosphere and the Topside Ionosphere-Plasmasphere: Observations and Model Simulations. Journal of Geophysical Research, 116, A12309.

[24] Qian, L., Burns, A.G., Solomon, S.C. and Chamberlin, P.C. (2012) Solar Flare Impacts on Ionospheric Electrodynamics. Geophysical Research Letters, 39, L06101.

[25] Solomon, S.C., Woods, T.N., Didkovsky, L.V., Emmert, J.T. and Qian, L. (2010) Anomalously Low Solar Extreme-Ultraviolet Irradiance and Thermospheric Density during Solar Minimum. Geophysical Research Letters, 37, L16103.

[26] Solomon, S.C., Qian, L., Didkovsky, L.V., Viereck, R.A. and Woods, T.N. (2011) Causes of Low Thermospheric Density during the 2007-2009 Solar Minimum. Journal of Geophysical Research, 116, A00H07. https://doi.org/10.1029/2011JA016508

[27] Burns, A.G., Solomon, S.C., Qian, L., Wang, W., Emery, B.A., Wiltberger, M. and Weimer, D.R. (2012) The Effects of Corotating Interaction Region/High Speed Stream Storms on the Thermosphere and Ionosphere during the Last Solar Minimum. Journal of Atmospheric and Solar-Terrestrial Physics, 83, 79-87.

[28] Ouattara, F. and Nanéma, E. (2014) Quiet Time foF2 Variation at Ouagadougou Station and Comparison with TIEGCM and IRI-2012 Predictions for 1985 and 1990. Physical Science International Journal, 4, 892-902. https://doi.org/10.9734/PSIJ/2014/9748

[29] Zerbo, J.L., Ouattara, F., Zoundi, C. and Gyébré, A. (2011) Solar Cycle 23 and Geomagnetic Activity since 1868. Revue du CAMES, 12, 255-262.

[30] Ouattara, F., Zoundi, C. and Fleury, R. (2012) Comparison between CODG TEC and GPS Based TEC Observations at Koudougou Station in Burkina Faso. Indian 
Journal of Radio \& Space Physics, 41, 617-623.

[31] Gnabahou, A. and Ouattara, F. (2012) Ionosphere Variability from 1957 to 1981 at Djibouti Station. European Journal of Scientific Research, 73, 382-390.

[32] Faynot, J.M. and Vila, P. (1979) F Region at the Magnetic Equator. Annals of Geophysics, 35, 1-9,

[33] Acharya, R., Sivaraman, M.R. and Dasgupta, A. (2011) On Conformity of the EEJ Based Ionospheric Model to the Fountain Effect and Resulting Improvements. Journal of Atmospheric and Solar-Terrestrial Physics, 73, 779-784. 